\title{
Education and neuroscience
}

\author{
Geoff Norman ${ }^{1}$
}

Published online: 18 November 2016

(C) Springer Science+Business Media Dordrecht 2016

Over the past decade or so, experimental psychology has undergone a small revolution. With the advent of sophisticated imaging technology, functional MRI, it is now possible to associate specific brain locations with different mental processes. While there have been some cautionary notes (Bennett et al. 2011) this does hold promise of providing another window on the mind. It is not, however, the first strategy to attempt to localize mental processes in space and time. Another technique, "Event Related Potentials" or ERP (Luck 2012) has been used for some time to associate different kinds of electrical activity with mental tasks.

Not surprisingly, there have been a few studies reported in the medical education literature (Durning et al. 2016), again not without their critics (Bordage and Eva 2016). Nevertheless, to many of us, much of this work appears about as transparent as quantum electrodynamics.

Hopefully, in this issue, we may clarify some of these difficult ideas. We have assembled four papers describing original; studies, by Hruska, Rourke and Young-Mee. Three involve fMRI; the fourth looks at ERPs. To help the reader decipher the methods and results, Anique de Bruin has written a thoughtful commentary. I hope you enjoy these cutting edge papers as much as I did.

\section{References}

Bennett, C. M., Baird, A. A., Miller, M. B., \& Wolford, G. L. (2011). Neural correlates of interspecies perspective taking in the post-mortem atlantic salmon: An argument for proper multiple comparisons correction. Journal of Serendipitous and Unexpected Results, 1, 1-5.

Bordage, G., \& Eva, K. (2016). Functional neuroimaging and diagnostic reasoning. Medical Teacher, 38, $752-753$.

Geoff Norman

norman@mcmaster.ca

1 McMaster University, Hamilton, ON, Canada 
Durning, S. J., Costanzo, M. E., Beckman, T. J., Artino, A. J., Jr., Roy, M. J., et al. (2016). Functional neuroimaging correlates of thinking flexibility and knowledge structure in memory: Exploring the relationships between clinical reasoning and diagnostic thinking. Medical Teacher, 38, 570-577.

Luck, S. J. (2012). Event-related potentials. In H. Cooper, P. M. Camic, D. L. Long, A. T. Panter, D. Rindskopf, \& K. J. Sher (Eds.), APA handbook of research methods in psychology: Volume 1, foundations, planning, measures, and psychometrics. Washington, DC: American Psychological Association. 